\title{
ASSESSING THE IMPACT OF THE 2009 H1N1 INFLUENZA PANDEMIC ON REPORTING OF OTHER THREATS THROUGH THE EARLY Warning and RESPONSE SYSTEM
}

\author{
A Cox ${ }^{1}$, P Guglielmetti², D Coulombier (Denis.Coulombier@ecdc.europa.eu) ${ }^{1}$ \\ 1. European Centre for Disease Prevention and Control, Stockholm, Sweden \\ 2. Health Threat Unit, European Commission, Luxembourg
}

This article was published on 12 November 2009.

Citation style for this article: Cox A, Guglielmetti P, Coulombier D. Assessing the impact of the 2009 H1N1 influenza pandemic on reporting of other threats through the Early Warning and Response System. Euro Surveill. 2009;14(45):pij=19397. Available online: http://www.eurosurveillance.org/ViewArticle.aspx?ArticleId=19397

Since the start of 2009 H1N1 influenza pandemic, a notable surge in messages communicated through the Early Warning and Response System (EWRS) for the prevention and control of communicable diseases in the European Union has been recorded. In order to measure the impact of this increase on the reporting of other events, we compared the messages posted in the EWRS since April 2009 with those posted in the previous years (2004-2008). The analysis revealed that a ten-fold increase in messages was recorded during the pandemic period, from April to September 2009, and that the reporting of other threats dropped to a significantly low rate. These results suggest an important impact on the notification process of events in case of a situation requiring extensive mobilisation of public health resources. It emphasises the importance keeping an appropriate balancing of resources during sustained emergencies, in particular in view of a possible second wave of pandemic influenza cases, to ensure prompt detection and reporting of potential concomitant emerging threats.

\section{Introduction}

The Early Warning and Response System (EWRS) was created in 1998 under Decision No 2119/98/EC of the European Parliament and of the Council with the aim of establishing a permanent communication between the public health authorities of the European Union (EU) Member States (MS) responsible for planning and taking measures to control the spread of communicable diseases in the European Community. Under this decision, the MS are required to inform each other and the European Commission (EC) in order to coordinate public health measures to control events caused by communicable diseases of relevance for the European Union [1]. In addition, specific planning for pandemic influenza by the EC designates the EWRS system as the primary network used by the MS for exchange of information and coordination of measures during an influenza pandemic [2]. Since its establishment in March 2005, the ECDC has been supporting the EC by operating the EWRS.

Since the first cases of pandemic 2009 H1N1 influenza reported in the United States on 24 April 2009 [3], the MS, the EC and the ECDC have relied heavily on EWRS to communicate messages related to the pandemic, with a significant increase in the number of messages posted on EWRS compared with the same period of the previous years. The objective of this study was to analyse the use of EWRS from April to end of September 2009 and to assess the impact of the ongoing $\mathrm{H} 1 \mathrm{~N} 1$ influenza pandemic on reporting of other events to be notified through the EWRS under the EU legislation on communicable diseases.

\section{Methods}

The MS, the EC and the ECDC exchange information through EWRS using three types of communications: messages sent to all users, selective exchanges between two or more users, and comments to existing messages. For this study, EWRS activity was quantified using the term "new event" defined as a message posted for all users by any user. Selective exchange messages and comments were excluded.

New events were aggregated on monthly intervals from May 2004 through September 2009. Data prior to May 2004 were not included in the review because of a major change in the reporting system preventing historical comparisons. A descriptive analysis of the 65-month series was performed in order to observe reporting trends. Monthly reporting activity in 2009 was compared with averages of corresponding months over the five previous years (2004-2008). Events related to pandemic H1N1 influenza were then removed from the data set in order to focus the analysis on the reporting pattern of non pandemic-related events.

A Poisson test was used to quantify the decrease in notification of non-pandemic events as compared with the average notification for the same period in previous years. Averages were compared for months before and during the pandemic. A $p<0.05$ was considered statistically significant.

\section{Results}

The analysis of the 65-month series, totalling 917 new events, indicates a very sharp increase in recent months corresponding with the start of the pandemic H1N1 influenza. In addition, a smaller increase can be noticed during the first six months of 2006, corresponding to events related to the introduction of avian influenza (H5N1) to Europe. The average number of new events posted per month during the pandemic period of April to September 2009 was 68.0 versus 8.6 during the preceding five years, indicating an unprecedented increase in reporting during the pandemic period. 
The average number of new events from 2004 to 2008 shows a seasonal pattern, with more new events being posted between June and October, on average. The maximum value observed in February 2006, 23 new events, corresponds to the avian influenza (H5N1) situation (Figure 1).

Significant deviation from expected seasonal reporting trends was observed during pandemic H1N1 influenza. Numbers indicated a dramatic increase in the total number of new events $(n=120$ in April 2009) and a historical low in the number of new events unrelated to pandemic H1N1 influenza (Figure 2).

The results of the Poisson probability test indicate that monthly event posting decreased significantly during March, June and July 2009 compared with the 2004-2008 averages (Table). These three months deviated from expected values with a $p<0.05$, indicating a significant decrease. Among the 48 new events reported in July,

\section{F I G U R E 1}

New events per month in the Early Warning and Response System (EWRS), May 2004 to September $2009(\mathbf{n}=917)$

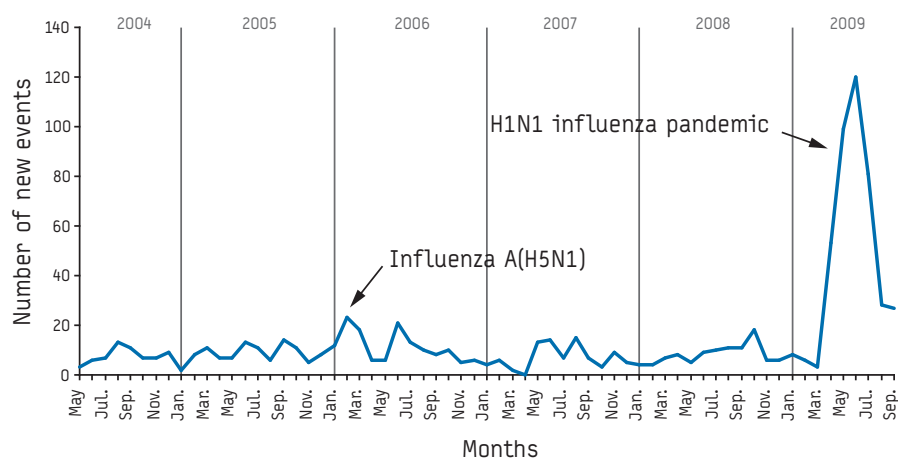

F I G U R E 2

Monthly average and range of non-pandemic related new events in the Early Warning and Response System (EWRS) in 2004-2008 vs. number of new events in 2009

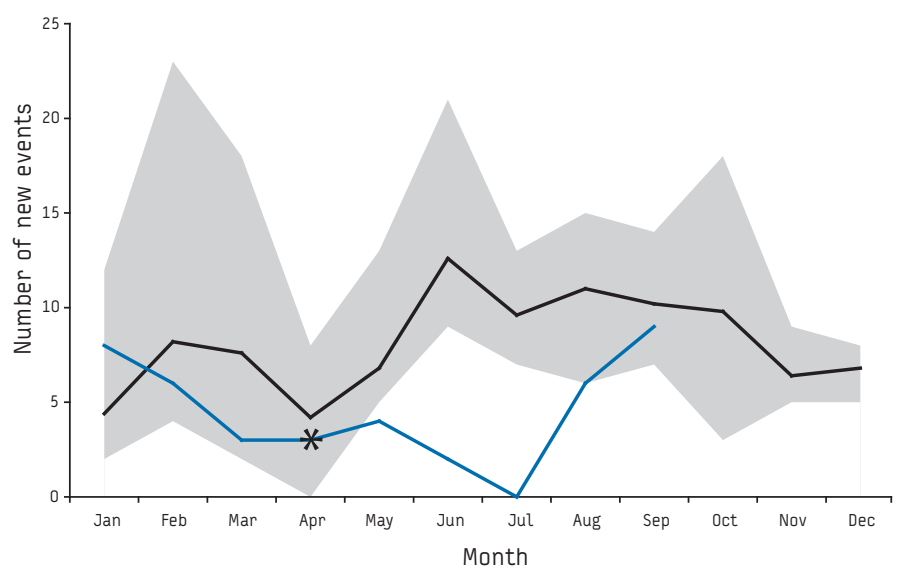

\footnotetext{
$\square$ Range of new events (2004-2008)

- Average new events (2004-2009)

- Non-pandemic - related new events (2009)

* Start of the pandemic in 2009
}

from 2004 to 2008, averaging 9.6 per month, 16 new events reported were related to food and water borne outbreaks (on average 3.2 per month), 8 were related to legionellosis cases (1.6 per month), 8 were related to vaccine preventable diseases ( 1.6 per month) and 16 were related to other conditions (3.2 per month).

\section{Discussion}

EWRS is known to be a very specific and reliable system, used to report confirmed events of European Community relevance requiring coordinated actions between the EU MS. EWRS has confirmed its value during the current pandemic, facilitating the necessary communications between MS, EC and ECDC to support implementation of rapid measures. However, on the basis of the results of our review, the dramatic increase in messages related to the current pandemic has masked a significant decrease in the reporting of other events. In July 2009, the number of nonpandemic related threads posted to EWRS dropped to zero. In August and September 2009, the number of new threads regained consistency with historical baseline values.

The decrease in March 2009 might be considered in the light of the high values reported in February and March 2006, related to avian influenza, which may have increased the historical baseline average value for these months. The significant decrease in the two consecutive months of June and July 2009 is extremely unlikely to be explained by chance alone.

In June and July 2009 several Member States were confronted with a dramatic increase in influenza cases. In this early stage of the H1N1 influenza pandemic, most Member States implemented a containment strategy aimed at preventing the introduction and community spread of the novel influenza virus. This strategy placed a tremendous strain on public health resources. During summer months, as cases tended to decrease during school holidays, most Member States discontinued active containment activities such as screening passengers and switched to a mitigation approach [4].

The concomitance of the dramatic decrease in notification of non-pandemic related threats during this period of extreme activity by national public health authorities suggests that the strain on

T A B L E

Poisson probability test indicating significance of decrease in monthly threat reporting in the Early Warning and Response System (EWRS) during 2009 compared with 20042008 averages

\begin{tabular}{|l|c|c|c|}
\hline Month & $\begin{array}{c}\text { 2004-2008 } \\
\text { Average }\end{array}$ & $\begin{array}{c}\text { Number of new events } \\
\text { (H1N1 influenza pandemic-related } \\
\text { events excluded) }\end{array}$ & -value \\
\hline January & 5.5 & 8 & 0.89 \\
\hline February & 10.3 & 6 & 0.12 \\
\hline March & 9.5 & 3 & $0.01^{*}$ \\
\hline April & 5.3 & 3 & 0.23 \\
\hline May & 6.8 & 4 & 0.19 \\
\hline June & 12.6 & 2 & $0.0003^{*}$ \\
\hline July & 9.6 & 0 & $0.00007^{\star}$ \\
\hline August & 11.0 & 6 & 0.08 \\
\hline September & 10.2 & 9 & 0.43 \\
\hline
\end{tabular}

* $p<0.05$ : significant value 
public health resources had an impact on the notification process of other events. However, other factors may have contributed to the decrease. It is possible that a public health crisis such as the pandemic H1N1 influenza would result in a decrease of nonessential reporting of new events. Even if not thoroughly evaluated, the review of new events posted during historical baseline period does not indicate a significant reporting of non-essential events, such as events not fulfilling the criteria for notification through EWRS. In addition, it is unlikely that the pandemic H1N1 influenza would result in a true reduction of other threats at a time where relatively few cases were occurring in the EU.

In March and April 2003, a five-fold increase in reporting of new events was noted, in relation with the emergence of the severe acute respiratory syndrome (SARS) epidemic. However, no significant decrease in reporting of other new events was noticed in the EWRS (unpublished data). This could be due to the fact that SARS only affected several MS and responded well to control measures.

\section{Conclusions}

These findings highlight the need to maintain awareness of potential emerging threats, especially in the context of an ongoing pandemic. The sustained nature of a pandemic necessitates that those in charge of threat detection and response keep a high level of vigilance. In preparation for the expected second wave of pandemic $\mathrm{H} 1 \mathrm{~N} 1$ influenza in the European Union, it is important to consider the consequences of possible concomitant events, should they occur. This is an ideal opportunity to revisit current pandemic plans, taking into account appropriate allocation of resources to ensure an optimal level of vigilance.

\section{References}

1. Decision no 2119/98/EC of the European Parliament and of the Council of 24 September 1998 setting up a network for the epidemiological surveillance and control of communicable diseases in the Community. Official Journal of the European Communities. 3 October 1998. Available from: http://eur-lex. europa.eu/pri/en/oj/dat/1998/l_268/l_26819981003en00010006.pdf.

2. Communication from the Commission to the Council, the European Parliament, the European Economic and Social Committee and the Committee of the Regions on pandemic influenza preparedness and response planning in the European Community. European Commission. 28 November 2005. Available from: http://eur-lex.europa.eu/LexUriServ/site/en/com/2005/com2005_0607en01.pdf

3. Centers for Disease Control and Prevention (CDC).Swine Influenza A (H1N1) Infection in two children --- Southern California, March--April 2009. MMWR Morb Mortal Wkly Rep. 2009;58(15):400-2.

4. Nicoll A, Coulombier D. Europe's initial experience with pandemic (H1N1) 2009 - mitigation and delaying policies and practices. Euro Surveill. 2009;14(29):pii=19279. Available from: http://www.eurosurveillance.org/ ViewArticle.aspx?ArticleId $=19279$ 